\title{
Genetics of plasma paroxonase activity
}

\author{
L ISELIUS, D A P EVANS, AND J R PLAYFER
}

From the Population Genetics Laboratory, University of Hawaii, Honolulu, Hawaii, USA; the Department of Clinical Genetics, Karolinska Hospital, Stockholm, Sweden; and the Nuffield Unit of Medical Genetics, Department of Medicine, University of Liverpool, Liverpool, UK.

SUMMARY Complex segregation analysis of plasma paroxonase activity gives evidence for a major locus with incomplete dominance $(\mathrm{d}=0 \cdot 70)$ causing high activity plus a background of multifactorial inheritance (heritability $=0 \cdot 09$ ).

The arylesterase paroxonase (EC 3.1.1.2) exhibits a genetic polymorphism with autosomal recessive inheritance of low paroxonase activity in plasma..$^{1-4}$ Although the distribution of plasma paroxonase activity shows bimodality ${ }^{3}$ or even trimodality ${ }^{2}$ the different subgroups are overlapping. This could result from methodological errors in the analysis or from other random environmental effects. However, it is also of interest to search for residual family resemblance owing to incomplete dominance and polygenes.

This paper describes a reanalysis of 40 British families described by Playfer $e t a l^{3}$ using complex segregation analysis. ${ }^{56}$

\section{Materials and methods}

The 40 nuclear families and methods of analysis of paroxonase activity have been described in detail before $^{3}$ and are also given in the appendix. For the genetic analysis the actual activity measurements were used instead of grouping the activities into high and low (or high, medium, and low) which decreases the power to discriminate between different hypotheses.

Complex segregation analysis of a quantitative trait depends upon normality assumptions and in particular skewness may simulate a major gene. ${ }^{7}$ Before entering segregation analysis the skewness was removed using the power transform $y=\mathrm{rp}^{-1}$ $\left[\left(\mathrm{xr}^{-1}+1\right)^{\mathrm{p}}-1\right]$ where $\mathrm{x}$ is the standardised (to mean zero and variance one) paroxonase activity and $r$ is a scale parameter introduced to insure that every $\left(\mathrm{xr}^{-1}+1\right)$ is positive in the sample. It was taken equal to 6 here. The standardised paroxonase activity without skewness is $y$. The parameter $p$ is estimated

Received for publication 11 March 1982. by maximum likelihood using the computer programme SKUMIX ${ }^{8}$ and was estimated to $0 \cdot 1128$.

Complex segregation analysis was performed under the mixed model, ${ }^{56}$ where segregation at a major locus, an additive multifactorial transmissible component, with generational differences and a random environmental component contribute independently to phenotype expression of a continuous trait. The model involves seven parameters: $U$, mean liability; $\mathrm{V}$, variance of liability; $\mathrm{H}$, the childhood multifactorial heritability; $\mathrm{HZ}$, the adult multifactorial heritability; q, gene frequency of the major locus; $t$, displacement owing to the major locus (measured in standard deviation units); and $d$, degree of dominance at the major locus (position of the heterozygous mean relative to the means of the two homozygous classes). Estimates of the parameters of the model are obtained by maximising the probability density of the observed phenotypes of the children conditional upon the phenotypes of the parents using the computer program POINTER. ${ }^{6}$ Since ascertainment was through the parents selection was taken as complete.

\section{Results}

No significant sex difference for paroxonase activity was noted. There was significant evidence $\left(\chi_{3}^{*}=\right.$ $51.77, p<0.001)$ for commingling of two distributions, which suggests a major locus but is neither necessary nor sufficient for the existence of a major gene.

Likelihoods and estimates of the parameters under different sub-hypotheses of the mixed model are given in the table. There was no significant evidence for generational differences for multifactorial heritability $\left(\chi_{1}^{2}=273 \cdot 16-272 \cdot 88=0 \cdot 28\right)$ and $Z$ was therefore set to one in the remaining analysis. The evidence for a major locus is strong $\left(\chi_{3}^{2}=273 \cdot 16-\right.$ 
TABLE Tests of hypotheses and estimates for the mixed model (values within parentheses correspond to non-iterated parameters).

\begin{tabular}{|c|c|c|c|c|c|c|}
\hline Hypothesis & $-2 \ln L+C$ & $H$ & $Z$ & $q$ & $t / \sqrt{v}$ & $d$ \\
\hline $\begin{array}{l}\mathrm{q}=0, \mathrm{Z}=1 \\
\text { No major locus, no intergenerational differences for } \\
\text { multifactorial heritability }\end{array}$ & $273 \cdot 16$ & 0.942 & (1) & (0) & (0) & (0) \\
\hline $\begin{array}{l}\mathrm{q}=0 \\
\text { No major locus }\end{array}$ & $272 \cdot 88$ & 0.748 & $1 \cdot 219$ & (0) & (0) & (0) \\
\hline $\begin{array}{l}\mathrm{H}=0 \\
\text { Generalised single locus }\end{array}$ & $237 \cdot 49$ & (0) & (1) & 0.266 & $2 \cdot 42$ & 0.691 \\
\hline $\begin{array}{l}\mathrm{d}=0 \\
\text { Recessive major locus }\end{array}$ & $261 \cdot 80$ & 0.210 & (1) & 0.676 & 1.66 & (0) \\
\hline $\begin{array}{l}\mathrm{d}=0.5 \\
\text { Additive major locus }\end{array}$ & $241 \cdot 19$ & $0 \cdot 101$ & (1) & 0.326 & $2 \cdot 76$ & $(0 \cdot 5)$ \\
\hline $\begin{array}{l}\mathrm{d}=1 \\
\text { Dominant major locus }\end{array}$ & $232 \cdot 14$ & $0 \cdot 109$ & (1) & 0.218 & 1.82 & (1) \\
\hline General model & $217 \cdot 83$ & 0.092 & (1) & 0.338 & $2 \cdot 36$ & 0.705 \\
\hline
\end{tabular}

$217 \cdot 83=55 \cdot 33, \mathrm{p}<0 \cdot 001)$. The best fit is with $\mathrm{d}=0.705$, that is, intermediate between an additive model $(\mathrm{d}=0.5)$ and a model with complete dominance $(\mathrm{d}=1)$ causing high paroxonase activity. There is significant evidence $\left(\chi_{1}^{2}=237.49-217.83\right.$ $=19.66, \mathrm{p}<0.001)$ for a small polygenic component $(\mathrm{H}=0.092)$.

Since segregation analysis gave support for a major locus using a $\mathrm{p}$ value for one distribution, the data were reanalysed using $p=-0.984$ obtained from SKUMIX assuming two distributions. This analysis would give more reliable estimates of the major locus parameters. However, the difference was minimal and the results of the second segregation analysis are therefore not given.

\section{Discussion}

There is good evidence that a major gene is involved in the regulation of plasma paroxonase activity. The characterisation of this gene has, however, been difficult. $^{2-4}$ This is not surprising since the methods used have been inefficient. Dichotomising or trichotomising quantitative data only decreases the possibilities of making meaningful genetic analyses. Elaborate statistical analysis of a frequency distribution to show bi- or trimodality ${ }^{2}$ is not likely to give further insight into the genetics of a particular trait, since the presence of several modes is not sufficient evidence for a major gene. Today, only segregation analysis under the mixed model ${ }^{56}$ can incorporate and test for complications like incomplete dominance and multifactorial heritability.

For plasma paroxonase activity the major gene has an effect in the heterozygote $(d=0.705)$. In addition, there is a background of multifactorial inheritance, with heritability $0 \cdot 094$, but with no evidence of an intergenerational difference. The estimate of the gene frequency, $0 \cdot 338$, is similar to the value estimated from the same data using a dichotomy, $0 \cdot 2966 .^{3}$

This work was supported by grant 3681 from the Swedish Medical Research Council and by grant GM 17173 from the US National Institutes of Health. PGL paper No 255.

\section{References}

1 Geldmacher-v Mallinckrodt M, Lindorf $\mathrm{HH}$, Petenyi M, Flügel M, Fischer T, Hiller T. Genetisch determinierter Polymorphismus der menschlichen Serum-Paraoxonase (EC 3.1.1.2). Humangenetik 1973;17:331.

2 Geldmacher-v Mallinckrodt M, Hommel G. Dumbach J. On the genetics of the human serum paraoxonase (EC 3.1.1.2). Hum Genet 1979;50:313-26.

3 Playfer JR, Eze LC, Bullen MF, Evans DAP. Genetic polymorphism and interethnic variability of plasma paroxonase activity. J Med Genet 1976;13:337-42.

4 Eiberg H, Mohr J. Genetics of paraoxonase. Ann Hum Genet $1981 ; 45: 323-30$.

5 Morton NE, MacLean CJ. Analysis of family resemblance. III. Complex segregation of quantitative traits. $\mathrm{Am} \mathrm{J}$ Hum Genet 1974;26:489-503.

${ }^{6}$ Lalouel JM, Morton NE. Complex segregation analysis with pointers. Hum Hered $1981 ; 31: 312-21$.

7 MacLean CJ, Morton NE, Lew R. Analysis of family resemblance. IV. Operational characteristics of segregation analysis. Am J Hum Genet 1975;27:365-84.

8 MacLean CJ, Morton NE, Elston RC, Yee S. Skewness in commingled distributions. Biometrics 1976; 32:695-9.

Requests for reprints to Dr L Iselius, Department of Clinical Genetics, Karolinska Hospital, S-10701 Stockholm 60, Sweden. 
APPENDIX Paroxonase activities in 40 British families. Values for female offspring are underlined.

\begin{tabular}{|c|c|c|c|c|c|c|c|c|}
\hline Family No & Father & Mother & & Offspring & & & & \\
\hline 1 & 884 & 945 & 851 & 1101 & 261 & & & \\
\hline 2 & 1089 & 608 & 631 & $\overline{1002}$ & & & & \\
\hline 3 & 1098 & 782 & 279 & $\overline{1055}$ & 1229 & 557 & $\underline{996}$ & \\
\hline 4 & 610 & 1047 & 1189 & 398 & & & & \\
\hline 5 & 854 & 999 & 1014 & $1 \overline{277}$ & 1277 & 336 & & \\
\hline 6 & 1083 & 806 & 438 & $\overline{1098}$ & & & & \\
\hline 7 & 740 & 744 & $\overline{325}$ & 737 & & & & \\
\hline 8 & 857 & 795 & 694 & 853 & & & & \\
\hline 9 & 736 & 889 & $\overline{860}$ & 704 & & & & \\
\hline 10 & 1252 & 1227 & $1 \overline{267}$ & 1348 & & & & \\
\hline 11 & 661 & 665 & $\overline{1149}$ & 731 & 768 & 1036 & 675 & 888 \\
\hline 12 & 274 & 399 & 473 & 477 & & & & \\
\hline 13 & 536 & 535 & $\overline{511}$ & 154 & & & & \\
\hline 14 & 362 & 204 & 358 & $\overline{368}$ & 365 & & & \\
\hline 16 & 474 & 316 & 492 & 294. & & & & \\
\hline 17 & 1500 & 422 & 980 & $1 \overline{256}$ & 1161 & & & \\
\hline 18 & 855 & 532 & 249 & 962 & & & & \\
\hline 19 & 956 & 204 & 183 & 845 & 989 & 802 & 191 & \\
\hline 20 & 723 & 315 & 220 & 746 & & & & \\
\hline 21 & 1282 & 414 & 897 & 802 & & & & \\
\hline 22 & 868 & 394 & $1 \overline{090}$ & 328 & & & & \\
\hline 23 & 817 & 317 & 295 & 795 & 266 & & & \\
\hline 24 & 1087 & 467 & $\overline{945}$ & 792 & 365 & & & \\
\hline 25 & 914 & 327 & 540 & 558 & & & & \\
\hline 26 & 1139 & 367 & 799 & $\overline{754}$ & & & & \\
\hline 27 & 733 & 466 & 977 & 793 & 368 & & & \\
\hline 28 & 790 & 315 & 723 & 425 & 425 & & & \\
\hline 29 & 1484 & 532 & $\overline{988}$ & $\underline{102}$ & & & & \\
\hline 30 & 1047 & 319 & $\underline{1028}$ & 852 & 1091 & & & \\
\hline 33 & 470 & 785 & $\overline{502}$ & 621 & & & & \\
\hline 34 & 412 & 1142 & 379 & $\overline{365}$ & 415 & & & \\
\hline 35 & 292 & 992 & 974 & $\overline{277}$ & 919 & & & \\
\hline 36 & 354 & 1054 & $\overline{1010}$ & 945 & & & & \\
\hline 37 & 301 & 1009 & 254 & & & & & \\
\hline 38 & 499 & 793 & 422 & 1340 & & & & \\
\hline 39 & 389 & 1307 & 514 & 657 & 350 & 646 & & \\
\hline 40 & 353 & 881 & $1 \overline{120}$ & 1252 & & & & \\
\hline
\end{tabular}

